\title{
Correlações canônicas entre caracteres morfológicos e componentes de produção em trigo de duplo propósito
}

\author{
Ivan Ricardo Carvalho(1), Velci Queiróz de Souza(1), Maicon Nardino(2), Diego Nicolau Follmann(1), \\ Denise Schmidt ${ }^{(1)}$ e Diego Baretta ${ }^{(2)}$
}

\begin{abstract}
(1)Universidade Federal de Santa Maria, Linha 7 de Setembro, BR 386, Km 40, s/no, CEP 98400-000 Frederico Westphalen, RS, Brasil. E-mail: carvalho.irc@gmail.com, velciq@gmail.com, diegonicolaufollmann@gmail.com, schmidtbr2000@yahoo.com.br (2)Universidade Federal de Pelotas, Centro de Genômica e Fitomelhoramento, Caixa Postal 354, CEP 96010-900 Capão do Leão, RS, Brasil. E-mail: nardinomn@gmail.com, barettadiego@gmail.com
\end{abstract}

Resumo - O objetivo deste trabalho foi identificar correlações canônicas entre caracteres morfológicos e componentes da produção de genótipos de trigo de duplo propósito, sob diferentes manejos de corte. Os experimentos foram realizados em 2013 e 2014, no delineamento de blocos ao acaso, em arranjo fatorial com cinco genótipos (BRS Tarumã, BRS Umbu, BRS Figueira, BRS Guatambu e BRS 277), quatro manejos de corte (sem corte, um corte, dois cortes e três cortes) e três repetições. Os grupos canônicos foram estabelecidos entre os caracteres morfológicos (grupo 1) e os componentes de produção (grupo 2). No grupo 1, foram avaliados número de perfilhos, diâmetro do colmo principal e dos perfilhos, e número de perfilhos férteis; no grupo 2, foram avaliados número de grãos por espiga e de espigas por metro quadrado, massa de grãos por espiga e de mil grãos, produtividade de grãos e peso hectolítrico. A correlação entre os grupos $1 \mathrm{e} 2$ depende do manejo de corte adotado. O diâmetro do colmo principal (nos manejos sem e com um corte), o diâmetro dos perfilhos (dois cortes), e o número total de perfilhos e de perfilhos férteis por planta (três cortes) devem ser priorizados para seleção de genótipos superiores quanto à produtividade de grãos e ao peso hectolítrico.

Termos para indexação: Triticum aestivum, análise multivariada, manejo de corte, seleção indireta.

\section{Canonical correlations between morphological traits and yield components in dual-purpose wheat}

\begin{abstract}
The objective of this work was to identify canonical correlations between morphological traits and yield components in dual-purpose wheat, under different cutting managements. The experiments were carried out in 2013 and 2014, under a complete block design, in a factorial arrangement with five genotypes (BRS Tarumã, BRS Umbu, BRS Figueira, BRS Guatambu, and BRS 277), four cutting managements (no cuts, one cut, two cuts, and three cuts), and three replicates. The canonical groups were established between morphological traits (group 1) and yield components (group 2). In group 1, number of tillers, diameter of the main stem and of the tillers, and number of fertile tillers were evaluated; in group 2, the number of grains per spike and of spikes per square meter, the mass of grains per spike and of a thousand grains, grain yield, and hectoliter weight were evaluated. The correlation between groups 1 and 2 depends on the adopted cutting management. The diameter of the main stem (in the managements without and with one cut), tiller diameter (two cuts), and the total number of tillers and of fertile tillers per plant (three cuts) should be prioritized for selection of superior genotypes as to grain yield and hectoliter weight.
\end{abstract}

Index terms: Triticum aestivum, multivariate analysis, cutting management, indirect selection.

\section{Introdução}

Os genótipos de trigo (Triticum aestivum L.) com dupla aptidão apresentam elevada produtividade de fitomassa, fase vegetativa longa, menor duração do período reprodutivo, tolerância ao pisoteio e ao manejo com cortes, alto potencial de perfilhamento e rápido estabelecimento da cultura (Martin et al., 2010).
As correlações canônicas permitem agrupar variáveis de interesse, de forma que a determinação das associações entre os grupos possibilite a seleção indireta de caracteres (Cruz et al., 2012) e, portanto, forneça informações valiosas para a seleção de ideótipos em programas de melhoramento. Esses estudos de correlação permitem identificar e quantificar as associações de caracteres morfológicos e produtivos 
com o desempenho das culturas. Erayman et al. (2006) realizaram a análise de correlação canônica para seleção de características relacionadas à germinação do trigo, enquanto Butt et al. (2001) a utilizaram para identificar relações entre caracteres bioquímicos e a qualidade de panificação do trigo.

Em razão da escassez de trabalhos sobre o tema em trigo de duplo propósito, a seleção de caracteres de interesse para a produtividade de grãos é promissora, especialmente se o manejo de cortes revelar respostas diferenciadas da relação entre os caracteres avaliados e a produtividade, conforme observado por Martin et al. (2013). Estes autores determinaram as relações entre vários caracteres produtivos e morfológicos do trigo por meio da análise de trilha. No entanto, não foram encontrados trabalhos nesse sentido que tenham utilizado a abordagem de correlações canônicas, a qual permite determinar as relações entre grupos de caracteres de importância para seleção de indivíduos superiores e facilita esse tipo de análise quando um grande número de caracteres é utilizado (Tavarez et al., 1999).

O objetivo deste trabalho foi identificar correlações canônicas entre caracteres morfológicos e componentes da produção de genótipos de trigo de duplo propósito, sob diferentes manejos de corte.

\section{Material e Métodos}

O experimento foi realizado em 2013 e 2014, na Universidade Federal de Santa Maria, em Frederico Westphalen, RS (2739'56"S, 5342'94"W, a 490 m de altitude). O solo do local é classificado como Latossolo Vermelho aluminoférrico, e o clima da região, como Cfa subtropical, de acordo com Köppen.

Utilizou-se o delineamento experimental de blocos ao acaso, em arranjo fatorial $5 \times 4$, com cinco genótipos (BRS Tarumã, BRS Umbu, BRS Figueira, BRS Guatambu e BRS 277), quatro manejos de corte (sem corte, um corte, dois cortes e três cortes) e três repetições. Os cortes foram realizados em plantas com altura média de $30 \mathrm{~cm}$, deixando-as com $10 \mathrm{~cm}$, para fins do rebrote (Martin et al., 2010).

As unidades experimentais foram compostas por 12 linhas de 2,0 $\mathrm{m}$ de comprimento, espaçadas em $17 \mathrm{~cm}$. A densidade de plantas utilizada para todos os genótipos avaliados foi de 3 milhões de plantas por hectare. Em ambas as safras analisadas, utilizou-se o sistema de semeadura direta, com adubação de base de $250 \mathrm{~kg} \mathrm{ha}^{-1}$ de NPK (10-20-20), além de $90 \mathrm{~kg} \mathrm{ha}^{-1}$ de $\mathrm{N}$ em cobertura, na forma de ureia $(45 \%$ de $\mathrm{N})$, parcelados com aplicação no pleno perfilhamento e após cada corte.

O controle de insetos-praga e doenças foi realizado de maneira preventiva. As avaliações foram realizadas nas seis linhas centrais de cada unidade experimental, tendo-se desprezado 0,50 m de cada extremidade. Dez plantas aleatórias foram amostradas em cada parcela, para avaliação dos caracteres (Martin et al., 2010, 2013).

Os seguintes caracteres foram avaliados: número de perfilhos por planta (AF); diâmetro dos perfilhos (DAF, em milímetros), medido no terço médio dos colmos; diâmetro do colmo principal (DCP, em milímetros), medido no terço médio; número de perfilhos férteis (AFF), contados em um metro; número de espigas por metro quadrado (EPM); número de grãos por espiga (NGE); massa de grãos por espiga (MGE, em gramas); massa de mil grãos (MMG, em gramas); produtividade de grãos ( $\mathrm{PG}$, em kg ha-1), com umidade corrigida para $13 \%$; e peso hectolítrico $(\mathrm{PH})$.

Os grupos canônicos foram estabelecidos a partir dos caracteres morfológicos (grupo 1) e dos componentes de produção (grupo 2). O grupo 1 foi composto pelos caracteres AF, DAF, DCP, e AFF; enquanto o grupo 2 foi composto por EPM, NGE, MGE, MMG, PG e PH (Cruz et al., 2012).

Os resultados foram submetidos à análise da correlação linear de Pearson (Steel et al., 1997). As correlações foram estimadas para cada manejo de corte, tendo-se utilizado os dados de 2 anos de cultivo, dos cinco genótipos de trigo duplo propósito e das três repetições, o que totalizou 30 observações. Realizouse o estudo da multicolinearidade entre os caracteres de cada grupo (Cruz \& Regazzi, 1997), e avaliou-se a homogeneidade de variância pelo teste de Bartlett (Steel et al., 1997). Os dados foram, então, submetidos à análise de variância e à análise de correlação canônica para cada manejo de corte. A verificação da significância entre os grupos de caracteres foi avaliada com base na estatística qui-quadrado (Cruz \& Regazzi, 1997). Após verificada a normalidade dos resultados, foi realizada a análise de multicolinearidade, tendo-se utilizado o número de condição (NC) como critério para verificar sua ocorrência (Cruz \& Carneiro, 2003). As análises foram realizadas com o programa Genes (Universidade Federal de Viçosa, Viçosa, MG).

Pesq. agropec. bras., Brasília, v.50, n.8, p.690-697, ago. 2015 DOI: 10.1590/S0100-204X2015000800007 


\section{Resultados e Discussão}

Para o manejo sem cortes, o NC foi de 36,25; para o de um corte, de 113,54; para o de dois cortes, de 74,76; e para o de três cortes, de 36,75. Dessa forma, optou-se por manter todas as variáveis na análise de correlação canônica (Toebe \& Cargnelutti Filho, 2013), uma vez que o atendimento do critério de multicolinearidade exerce maior efeito do que a não normalidade multivariada e, portanto, gera maior confiabilidade das estimativas.

A correlação linear de Pearson revelou, para o manejo sem cortes, 28 correlações significativas; para o manejo com um corte, 29 correlações significativas (Tabela 1); para o com dois cortes, 16 correlações significativas; e para o com três cortes, 27 correlações significativas (Tabela 2).

Estudos como o de Lopes et al. (2012) mostram a importância desse tipo de resultado para o melhoramento genético do trigo. Com relação ao efeito dos cortes sobre a produtividade de grãos de trigo, Gondim et al. (2008) observaram que a retirada da área foliar do trigo é determinante para a redução da massa de mil grãos e do número de grãos por espiga, e que o decréscimo na produtividade está relacionado à menor massa de matéria seca do colmo. Souza et al. (2013) demonstraram que a retirada do limbo foliar do trigo diminui a produtividade de grãos, o número e a massa de grãos da espiga, bem como o peso hectolítrico.

Quatro pares canônicos entre caracteres do grupo 1 e 2 foram significativos para o manejo sem cortes (Tabela 3). Para os manejos com um, dois e três cortes, foram observados três pares canônicos significativos (Tabelas 3 e 4). A elevada magnitude dos coeficientes de correlação canônica evidenciou alta dependência entre os dois grupos de caracteres.

O manejo sem cortes apresentou correlação $\mathrm{r}=1,00$ entre os grupos, por meio do primeiro par canônico(Tabela3). Odiâmetrodos colmos dos perfilhos (grupo 1) esteve diretamente relacionado à massa de grãos por espiga e ao peso hectolítrico, mas inversamente relacionado ao número de espigas por metro quadrado e à massa de mil grãos (grupo 2). Gondim et al. (2008) verificaram que a produtividade de grãos no trigo é explicada pelas dimensões e pelo acúmulo de reservas nos colmos. Já para Valério et al. (2009), o incremento na produtividade está aliado ao maior número e massa de grãos por espiga.

Genótipos de trigo com duplo propósito com menor emissão de perfilhos por planta tiveram menor diâmetro do colmo dos perfilhos, o que influenciou a produtividade da cultura. Almeida \& Mundstock (2001) apontaram que o número e as proporções morfológicas dos perfilhos podem estar relacionados ao armazenamento de fotoassimilados e ao carreamento destes para o colmo principal, quando necessário. Valério et al. (2008) relataram que o número de perfilhos por planta contribui para a obtenção de maior número de espigas por área e que, quando estas são férteis, obviamente há aumento na produtividade de grãos.

O segundo par canônico apresentou correlação $\mathrm{r}=1,00$ entre os grupos (Tabela 3). O número de perfilhos férteis por planta (grupo 1) esteve diretamente relacionado ao número de espigas por

Tabela 1. Correlações fenotípicas entre caracteres morfológicos (grupo 1) e agronômicos (grupo 2), analisados em cinco genótipos de trigo (Triticum aestivum) de duplo propósito, nos manejos sem (diagonal superior) e com um corte (diagonal inferior $)^{(1)}$.

\begin{tabular}{|c|c|c|c|c|c|c|c|c|c|c|}
\hline & EPM & $\mathrm{PH}$ & MMG & PG & NGE & MGE & $\mathrm{AF}$ & $\mathrm{DCP}$ & DAF & $\mathrm{AFF}$ \\
\hline EPM & - & $-0,69^{*}$ & $-0,15$ & $0,90 *$ & $0,50 *$ & 0,31 & $-0,27$ & 0,27 & $-0,29$ & $0,97 *$ \\
\hline $\mathrm{PH}$ & $0,68 *$ & - & 0,34 & $-0,57^{*}$ & $-0,62 *$ & $-0,46^{*}$ & $-0,22$ & 0,03 & 0,25 & $-0,75^{*}$ \\
\hline MMG & 0,03 & $0,49 *$ & - & 0,18 & $0,51 *$ & $0,61^{*}$ & $-0,69 *$ & $0,43 *$ & $0,95^{*}$ & $-0,35$ \\
\hline PG & $0,79^{*}$ & $0,73^{*}$ & $0,44^{*}$ & - & $0,70^{*}$ & $0,62^{*}$ & $-0,62 *$ & $0,64^{*}$ & 0,00 & $0,78^{*}$ \\
\hline NGE & 0,23 & 0,01 & 0,32 & $0,66^{*}$ & - & $0,96 *$ & $-0,44 *$ & $0,46^{*}$ & $0,53 *$ & 0,37 \\
\hline MGE & 0,27 & 0,29 & $0,71 *$ & $0,75^{*}$ & $0,89^{*}$ & - & $-0,56^{*}$ & $0,60 *$ & $0,62^{*}$ & 0,15 \\
\hline $\mathrm{AF}$ & $-0,64 *$ & $-0,13$ & $-0,21$ & $-0,51 *$ & $-0,44 *$ & $-0,49 *$ & - & $-0,90 *$ & $-0,45^{*}$ & $-0,04$ \\
\hline DCP & $0,47 *$ & $0,69^{*}$ & $0,75^{*}$ & $0,47 *$ & $-0,05$ & 0,37 & $-0,51^{*}$ & - & 0,21 & 0,08 \\
\hline DAF & 0,06 & $0,42 *$ & $0,64^{*}$ & $0,64 *$ & $0,70 *$ & $0,80^{* *}$ & 0,09 & 0,14 & - & $-0,45^{*}$ \\
\hline $\mathrm{AFF}$ & $0,78^{*}$ & $0,90 *$ & $0,53 *$ & $0,70 *$ & 0,01 & 0,33 & $-0,50 *$ & $0,89 *$ & 0,19 & - \\
\hline
\end{tabular}

${ }^{(1)}$ Grupo 1: AF, número de perfilhos por planta; DCP, diâmetro do colmo principal; DAF, diâmetro de perfilhos; e AFF, número de perfilhos férteis por planta. Grupo 2: EPM, número de espigas por metro quadrado; PH, peso hectolítrico; MMG, massa de mil grãos; PG, produtividade de grãos; NGE, número de grãos por espiga; e MGE, massa de grãos por espiga. *Significativo pelo teste $\mathrm{t}(\mathrm{n}=30)$, a $5 \%$ de probabilidade. 
planta e à produtividade de grãos, mas inversamente relacionado ao peso hectolítrico, à massa de mil grãos, e ao número e à massa de grãos por espiga (grupo 2). O número de perfilhos férteis depende das características intrínsecas do genótipo e do ambiente de cultivo (Ozturk et al., 2006). Desse modo, acréscimos nessa variável reduziram o peso hectolítrico e as dimensões das espigas, e resultaram em grãos mais leves, com menos grãos por espiga. Valério et al. (2008) constataram que o aumento no número de perfilhos férteis promove competição entre as plantas e redução da eficiência fotossintética e redução no acúmulo de assimilados nas estruturas reprodutivas.

O terceiro par canônico apresentou correlação $\mathrm{r}=1,00$ entre os grupos (Tabela 3). Observou-se que maiores diâmetros do colmo principal (grupo 1) favoreceram a obtenção de maior número de espigas por metro quadrado, massa de mil grãos, produtividade de grãos, e número e massa de grãos por espiga, mas diminuíram o peso hectolítrico (grupo 2).

Plantas com menor emissão de perfilhos tendem a favorecer o desenvolvimento do colmo principal. De acordo com Santos \& Mundstock (2002), modificações nas estruturas morfológicas do trigo decorrem de diferenças nas condições do manejo, na densidade de semeadura e na capacidade competitiva e de compensação (plasticidade fenotípica) das cultivares. Falqueto et al. (2009) argumentaram que a produtividade é fortemente influenciada pela eficiência das plantas em direcionar seus assimilados para estruturas específicas, bem como pela capacidade de modificar este carreamento ao longo de seus estádios fenológicos, nas diferentes condições do ambiente.

$\mathrm{O}$ quarto par canônico apresentou correlação $\mathrm{r}=0,99$ (Tabela 3). O número de perfilhos por planta (grupo 1) esteve diretamente relacionado ao número de espigas por metro quadrado e ao número e à massa de grãos por espiga, e inversamente relacionado ao peso hectolítrico e à massa de mil grãos (grupo 2). Portanto, o aumento no número de espigas e no número e na massa de grãos por planta resultou no fracionamento dos fotoassimilados em estruturas morfológicas dispendiosas, o que teria reduzido a massa e o peso hectolítrico dos grãos.

A capacidade de perfilhamento tem caráter compensatório ao longo do desenvolvimento fenológico das plantas e, dada sua forte influência sobre a quantidade de espigas por planta, ela é importante para regular a sobrevivência dos perfilhos. Perfilhos autossuficientes e fotossinteticamente ativos tendem a contribuir para aumento na produtividade de grãos (Fioreze \& Rodrigues, 2012).

Portanto, para o manejo sem cortes, a melhor associação entre os grupos foi estabelecida com o diâmetro do colmo principal; dessa forma, esse caráter tem bastante relevância para a seleção indireta com o intuito de aumentar o número de espigas por planta, o número e a massa de grãos por espiga, a massa de mil grãos, o peso hectolítrico e a produtividade de grãos do trigo de duplo propósito.

Para o manejo com um corte, as associações estabelecidas por meio do primeiro par canônico apresentaram correlação $r=1,00$ entre os grupos

Tabela 2. Correlações fenotípicas entre caracteres morfológicos (grupo 1) e agronômicos (grupo 2), analisados em cinco genótipos de trigo (Triticum aestivum) de duplo propósito, nos manejos com dois (diagonal superior) e três cortes (diagonal inferior) $)^{(1)}$.

\begin{tabular}{lccccccccccc}
\hline & EPM & PH & MMG & PG & NGE & MGE & AF & DCP & DAF & AFF \\
\hline EPM & - & 0,34 & 0,02 & $0,75^{*}$ & $-0,07$ & $-0,31$ & 0,12 & $-0,42^{*}$ & $-0,21$ & 0,35 \\
PH & $0,52^{*}$ & - & 0,14 & $0,86^{*}$ & $0,51^{*}$ & 0,33 & $-0,52^{*}$ & 0,24 & 0,05 & $-0,23$ \\
MMG & $0,74^{*}$ & $0,76^{*}$ & - & 0,02 & 0,20 & $0,58^{*}$ & $-0,37$ & 0,06 & $0,94^{*}$ & $0,47^{*}$ \\
PG & 0,23 & $-0,03$ & 0,21 & - & 0,22 & $-0,04$ & $-0,35$ & 0,04 & $-0,18$ & 0,05 \\
NGE & $0,51^{*}$ & $0,86^{*}$ & $0,43^{*}$ & $-0,11$ & - & $0,87^{*}$ & 0,22 & $-0,40^{*}$ & $0,40^{*}$ & $-0,73^{*}$ \\
MGE & $0,53^{*}$ & 0,18 & 0,07 & $0,62^{*}$ & $0,47^{*}$ & - & 0,00 & $-0,19$ & $0,78^{*}$ & $-0,44^{*}$ \\
AF & 0,06 & $0,88^{*}$ & $0,48^{*}$ & $-0,15$ & $0,72^{*}$ & $-0,08$ & - & $-0,90^{*}$ & $-0,21$ & $-0,39^{*}$ \\
DCP & 0,25 & $-0,25$ & 0,32 & $-0,23$ & $-0,52^{*}$ & $-0,52^{*}$ & $-0,44^{*}$ & - & $-0,03$ & 0,27 \\
DAF & $0,48^{*}$ & $0,49 *$ & $0,64^{*}$ & $-0,58^{*}$ & 0,28 & $-0,44^{*}$ & 0,30 & $0,62^{*}$ & - & 0,21 \\
AFF & $0,60^{*}$ & $-0,17$ & $0,40^{*}$ & $0,68^{*}$ & $-0,29$ & $0,41^{*}$ & $-0,53^{*}$ & $0,47^{*}$ & $-0,03$ & - \\
\hline
\end{tabular}

${ }^{(1)}$ Grupo 1: AF, número de perfilhos por planta; DCP, diâmetro do colmo principal; DAF, diâmetro de perfilhos; e AFF, número de perfilhos férteis por planta. Grupo 2: EPM, número de espigas por metro quadrado; PH, peso hectolítrico; MMG, massa de mil grãos; PG, produtividade de grãos; NGE, número de grãos por espiga; e MGE, massa de grãos por espiga. *Significativo pelo teste $t(n=30)$, a $5 \%$ de probabilidade. 
(Tabela 3). O trigo de duplo propósito geralmente apresenta tolerância ao desfolhamento e capacidade de recuperação da área foliar (Bortolini et al., 2004). No manejo com um corte, o diâmetro do colmo dos perfilhos (grupo 1) esteve diretamente relacionado à massa de grãos na espiga e à massa de mil grãos, mas inversamente relacionado ao número de espigas por metro quadrado, ao peso hectolítrico e à produtividade de grãos (grupo 2).

Martin et al. (2010) concluíram que os componentes da produção do trigo de duplo propósito são fortemente influenciados pela capacidade de perfilhamento do

Tabela 3. Cargas dos caracteres morfológicos (grupo 1) e agronômicos (grupo 2) nas correlações canônicas (r) entre os grupos, em cinco genótipos de trigo (Triticum aestivum) de duplo propósito, nos manejos sem e com um corte.

\begin{tabular}{|c|c|c|c|c|}
\hline \multirow[t]{2}{*}{ Caráter $^{(1)}$} & \multicolumn{4}{|c|}{ Par canônico } \\
\hline & $1^{\circ} \stackrel{0}{1}$ & $2^{\circ}$ & 3o & $4^{\circ}$ \\
\hline & \multicolumn{4}{|c|}{ Manejo sem cortes } \\
\hline \multicolumn{5}{|l|}{ Grupo 1} \\
\hline $\mathrm{AF}$ & $-0,2957$ & 0,0543 & $-0,7891$ & 0,5353 \\
\hline DAF & 0,6445 & 0,0531 & 0,7131 & $-0,2704$ \\
\hline DCP & $-0,2370$ & $-0,8065$ & 0,5286 & $-0,1173$ \\
\hline $\mathrm{AFF}$ & $-0,2585$ & 0,8511 & 0,3791 & 0,2547 \\
\hline \multicolumn{5}{|l|}{ Grupo 2} \\
\hline EPM & $-0,2109$ & 0,7791 & 0,5710 & 0,1495 \\
\hline $\mathrm{PH}$ & 0,1167 & $-0,4490$ & $-0,3454$ & $-0,8160$ \\
\hline MMG & $-0,1595$ & $-0,6484$ & 0,6544 & $-0,3547$ \\
\hline PG & 0,0391 & 0,5351 & 0,8422 & 0,0528 \\
\hline NGE & $-0,0730$ & $-0,1177$ & 0,8845 & 0,4459 \\
\hline MGE & 0,1309 & $-0,2794$ & 0,8799 & 0,3612 \\
\hline $\mathrm{r}$ & 1,0000 & 1,0000 & 1,0000 & 0,9990 \\
\hline p & $<0,0100$ & $<0,0100$ & $<0,0100$ & $<0,0100$ \\
\hline & \multicolumn{4}{|c|}{ Manejo com um corte } \\
\hline \multicolumn{5}{|l|}{ Grupo 1} \\
\hline $\mathrm{AF}$ & $-0,1000$ & $-0,5909$ & $-0,0953$ & 0,7947 \\
\hline DAF & 0,3655 & 0,7850 & 0,4973 & 0,0524 \\
\hline DCP & 0,0954 & $-0,4287$ & 0,8944 & $-0,0834$ \\
\hline $\mathrm{AFF}$ & $-0,0890$ & 0,7937 & 0,6012 & 0,0243 \\
\hline \multicolumn{5}{|l|}{ Grupo 2} \\
\hline EPM & $-0,5560$ & 0,6385 & 0,3934 & $-0,3579$ \\
\hline $\mathrm{PH}$ & $-0,2782$ & 0,5080 & 0,7684 & 0,2719 \\
\hline MMG & 0,6515 & 0,1775 & 0,7362 & 0,0407 \\
\hline PG & $-0,3017$ & 0,2374 & 0,8289 & $-0,4064$ \\
\hline NGE & 0,0292 & $-0,3669$ & 0,5381 & $-0,7581$ \\
\hline MGE & 0,2932 & $-0,1103$ & 0,7602 & $-0,5691$ \\
\hline $\mathrm{r}$ & 1,0000 & 1,0000 & 0,9990 & 0,9990 \\
\hline $\mathrm{p}$ & $<0,0100$ & $<0,0100$ & $<0,0100$ & 0,3200 \\
\hline
\end{tabular}

${ }^{(1)}$ Grupo 1: AF, número de perfilhos por planta; DAF, diâmetro de perfilhos; DCP, diâmetro do colmo principal; e AFF, número de perfilhos férteis por planta. Grupo 2: EPM, número de espigas por metro quadrado; $\mathrm{PH}$, peso hectolítrico; MMG, massa de mil grãos; PG, produtividade de grãos; NGE, número de grãos por espiga; e MGE, massa de grãos por espiga. genótipo, pela disponibilidade hídrica e nutricional, pela qualidade e pela quantidade de luz, pela temperatura e pelo número de cortes realizados.

O segundo par canônico apresentou correlação $r=1,00$ entre os grupos (Tabela 3). As plantas submetidas ao manejo com um corte emitiram menos perfilhos e minimizaram a utilização de assimilados em estruturas não produtivas. A diminuição no número de perfilhos totais por planta (grupo 1), no entanto, aumentou o número de espigas por metro quadrado, em razão do aumento no número de perfilhos férteis. Além disso, o peso hectolítrico, a massa de mil grãos e a produtividade

Tabela 4. Cargas dos caracteres morfológicos (grupo 1) e agronômicos (grupo 2) nas correlações canônicas (r) entre os grupos, em cinco genótipos de trigo (Triticum aestivum) de duplo propósito, nos manejos com dois e três cortes.

\begin{tabular}{|c|c|c|c|c|}
\hline \multirow[t]{2}{*}{ Caráter $^{(1)}$} & \multicolumn{4}{|c|}{ Par canônico } \\
\hline & $1 \stackrel{\circ}{a}$ & $2 \mathrm{o}$ & 3o & 40 \\
\hline & \multicolumn{4}{|c|}{ Manejo com dois cortes } \\
\hline \multicolumn{5}{|l|}{ Grupo 1} \\
\hline $\mathrm{AF}$ & 0,0817 & $-0,4142$ & $-0,8855$ & 0,1935 \\
\hline DAF & $-0,3500$ & 0,5797 & 0,7299 & 0,0920 \\
\hline DCP & 0,9349 & 0,0952 & 0,3095 & 0,1447 \\
\hline AFF & $-0,0230$ & $-0,5664$ & 0,7712 & 0,2895 \\
\hline \multicolumn{5}{|l|}{ Grupo 2} \\
\hline EPM & $-0,0862$ & $-0,7894$ & 0,0914 & $-0,6066$ \\
\hline $\mathrm{PH}$ & 0,0853 & 0,2906 & 0,2587 & $-0,9246$ \\
\hline MMG & 0,8284 & $-0,0922$ & 0,5501 & 0,0431 \\
\hline PG & $-0,1133$ & $-0,1911$ & 0,2665 & $-0,9499$ \\
\hline NGE & 0,6225 & 0,3552 & $-0,4710$ & $-0,5196$ \\
\hline MGE & 0,8698 & 0,4242 & $-0,1601$ & $-0,1959$ \\
\hline $\mathrm{r}$ & 1,0000 & 0,9990 & 0,9990 & 0,9900 \\
\hline $\mathrm{p}$ & $<0,0100$ & $<0,0100$ & $<0,0100$ & $>0,0600$ \\
\hline & \multicolumn{4}{|c|}{ Manejo com três cortes } \\
\hline \multicolumn{5}{|l|}{ Grupo 1} \\
\hline $\mathrm{AF}$ & 0,5612 & $-0,3262$ & 0,7597 & $-0,0357$ \\
\hline DAF & $-0,2109$ & 0,9042 & $-0,0174$ & 0,3709 \\
\hline DCP & $-0,0070$ & 0,7123 & 0,7014 & $-0,0229$ \\
\hline AFF & 0,3436 & 0,6330 & $-0,6835$ & -01177 \\
\hline \multicolumn{5}{|l|}{ Grupo 2} \\
\hline EPM & 0,3967 & 0,6401 & 0,0232 & $-0,6596$ \\
\hline PH & 0,6562 & 0,0290 & 0,6683 & 0,3502 \\
\hline MMG & 0,7369 & 0,5759 & 0,3359 & $-0,1113$ \\
\hline PG & 0,6722 & $-0,0858$ & $-0,7331$ & $-0,0552$ \\
\hline NGE & 0,3650 & $-0,1846$ & 0,5610 & $-0,7220$ \\
\hline MGE & 0,3322 & $-0,1813$ & $-0,4647$ & $-0,8044$ \\
\hline$\underline{r}$ & 1,0000 & 1,0000 & 0,9990 & 0,9963 \\
\hline $\mathrm{p}$ & $<0,0100$ & $<0,0100$ & $<0,0100$ & $>0,0600$ \\
\hline
\end{tabular}

${ }^{(1)}$ Grupo 1: AF, número de perfilhos por planta; DAF, diâmetro de perfilhos; DCP, diâmetro do colmo principal; e AFF, número de perfilhos férteis por planta. Grupo 2: EPM, número de espigas por metro quadrado; $\mathrm{PH}$, peso hectolítrico; MMG, massa de mil grãos; PG, produtividade de grãos; NGE, número de grãos por espiga; e MGE, massa de grãos por espiga. 
também foram favorecidos pela diminuição nessa variável que, contudo, resultou na diminuição no número e na massa de grãos por espiga (grupo 2).

Ainda no segundo par canônico, observou-se que o aumento no número de perfilhos férteis (grupo 1), nas plantas submetidas a um corte, favoreceu $o$ aumento no número de espigas por metro quadrado, no peso hectolítrico, na massa de mil grãos e na produtividade, mas diminuiu o número e a massa de grãos por espiga (grupo 2). Portanto, a seleção de genótipos com duplo propósito pode basear-se na escolha de plantas com elevada formação de perfilhos férteis, o que contribuiria indiretamente para melhor desempenho das estruturas reprodutivas por planta, mas com reflexos negativos na dimensão das espigas, em decorrência do fracionamento dos assimilados. Silveira et al. (2010) verificaram a influência direta do número de perfilhos férteis sobre o número de espigas por área e de grãos por espiga, bem como sobre a massa dos grãos.

Para o terceiro par canônico, constatou-se correlação $r=0,99$ entre os grupos (Tabela 3). O diâmetro do colmo principal (grupo 1), no manejo com um corte, esteve diretamente relacionado ao número de espigas por metro quadrado, ao número e à massa de grãos por espiga, à massa de mil grãos, ao peso hectolítrico e à produtividade de grãos (grupo 2).

Silva et al. (2005) apontaram que o número de grãos por espiga constitui o caráter mais promissor para a seleção indireta, para aumento na produtividade. No presente trabalho, a seleção baseada no diâmetro do colmo principal poderia contribuir indiretamente para a formação de espigas e para o número e a massa de grãos por espiga, com reflexos positivos para a produtividade.

Conforme Martin et al. (2010), o manejo com um corte diminui a magnitude de todos os componentes de produção, em razão da utilização de fotoassimilados para a recomposição da área foliar.

O manejo com um corte, portanto, evidenciou melhor associação entre os grupos de caracteres na avaliação do caráter diâmetro do colmo principal; assim, a seleção indireta deste caráter incrementaria o número de espigas por planta, o número e a massa de grãos da espiga, a massa de mil grãos, o peso hectolítrico e o rendimento de grãos.

O manejo com dois cortes resultou em correlação $\mathrm{r}=1,00$ entre os grupos, para o primeiro par canônico
(Tabela 4). O diâmetro do colmo principal (grupo 1) nesse manejo esteve diretamente relacionado ao número e à massa de grãos por espiga, e à massa de mil grãos; apesar disso, esteve inversamente relacionado à produtividade (grupo 2). Genótipos de duplo propósito submetidos a dois cortes reduzem a taxa fotossintética, o que modifica a partição de fotoassimilados na planta (Bortolini et al., 2004).

O segundo par canônico apresentou correlação $=1,00$ entre os grupos (Tabela 4). O número de perfilhos e de perfilhos férteis (grupo 1) no manejo com dois cortes esteve diretamente relacionado ao número e à massa de grãos por espiga, bem como ao peso hectolítrico, mas esteve inversamente relacionado ao número de espigas por metro quadrado e à produtividade de grãos (grupo 2).

Valério et al. (2009) afirmaram que, apesar de a produtividade de grãos em trigo ser dependente do aumento no número de grãos por área, de grãos por espiga e de perfilhos por planta, esse aumento não pode comprometer o atendimento da demanda por fotoassimilados do colmo principal. Perfilhos não autossuficientes constituem drenos para as plantas, o que compromete sua dinâmica fisiológica $\mathrm{e}$ fotossintética, e prejudica o desempenho de caracteres associados à espiga e à produtividade. Alves et al. (2004) relataram que perfilhos férteis podem contribuir não somente com o aumento no número de grãos por planta, mas, também, com o incremento da área foliar e da taxa de assimilação fotossintética das plantas.

$\mathrm{O}$ terceiro par canônico apresentou correlação $\mathrm{r}=0,99$ entre os grupos (Tabela 4). $\mathrm{O}$ diâmetro de colmos dos perfilhos (grupo 1), no manejo com dois cortes, relacionou-se diretamente ao peso hectolítrico, à massa de mil grãos e à produtividade de grão do trigo, mas inversamente ao número e à massa de grãos por espiga (grupo 2).

De acordo com Valério et al. (2009), o ideótipo para produção de grãos em trigo é caracterizado pela capacidade de manter a estrutura reprodutiva do colmo principal, associada a dois ou três perfilhos férteis.

Martin et al. (2013) observaram que o número de cortes, em trigo de duplo propósito, diminui a área foliar fotossinteticamente ativa, com consequências diretas para o balanço fisiológico entre fontes e drenos, e para a partição de fotoassimilados na planta.

Para o manejo com dois cortes, portanto, as melhores associações foram estabelecidas com o uso do diâmetro 
do colmo dos perfilhos, em que a seleção indireta pode ser realizada para aumentar a massa de mil grãos, o peso hectolítrico e a produtividade de grãos.

Para o manejo com três cortes, portanto, a correlação entre os grupos para o primeiro par canônico foi $r=1,00$ (Tabela 4). O número de perfilhos e de perfilhos férteis (grupo 1), com esse manejo de corte, esteve diretamente relacionado ao número de espigas por metro quadrado, ao número e à massa de grãos por espiga, à massa de mil grãos, à produtividade e ao peso hectolítrico (grupo 2).

Bortolini et al. (2004) verificaram que o trigo de duplo propósito submetido a múltiplos cortes aumenta o peso hectolítrico mas, em contrapartida, diminui a massa de mil grãos. Segundo Gondim et al. (2008), a seleção de genótipos mais produtivos e que tolerem a retirada do limbo foliar pode ser feita com base no caráteres massa de mil grãos e quantidade de grãos por espiga.

Souza et al. (2013) concluíram que a retirada da área foliar do trigo pode comprometer até $20 \%$ da produção de grãos, em razão da diminuição no número e na massa de grãos dos perfilhos.

Dessa forma, essa correlação canônica para o primeiro par, no manejo com três cortes, indica que genótipos com maior capacidade de emitir perfilhos autosuficientes em termos fotossintéticos tendem a originar estruturas reprodutivas com maior tamanho de espigas e, portanto, com maior número e massa de grãos por planta, e, consequentemente, com maior produtividade.

O segundo par canônico apresentou correlação $\mathrm{r}=1,00$ entre os grupos (Tabela 4). O número de perfilhos férteis (grupo 1) relacionou-se diretamente ao número de espigas por metro quadrado e à massa de mil grãos, mas inversamente ao número e à massa de grãos por espiga (grupo 2). Vieira et al. (2007) observaram que a quantidade de perfilhos férteis em trigo tem efeitos diretos elevados e positivos sobre a produtividade de grãos. Esta relação canônica mostra que a seleção de genótipos superiores, no manejo com três cortes, pode ser direcionada para plantas com maior sobrevivência e formação de perfilhos férteis.

A sobrevivência de perfilhos está associada à qualidade e à quantidade da luz incidente, à competição inter e intraespecífica, e aos manejos culturais (Valério et al., 2009).

O terceiro par canônico apresentou correlação $\mathrm{r}=0,99$ entre os grupos (Tabela 4). O diâmetro do colmo principal (grupo 1), no manejo com três cortes, relacionou-se diretamente ao número de espigas por metro quadrado, à massa de mil grãos e ao peso hectolítrico, mas inversamente à massa de grãos por espiga e à produtividade de grãos (grupo 2). Souza et al . (2013) também relataram correlações significativas entre o diâmetro do colmo e os caracteres associados ao armazenamento de fotoassimilados.

Desse modo, a seleção baseada no diâmetro do colmo principal, no manejo com três cortes, é adequada para o aumento no número de grãos por espiga, na massa de mil grãos e no peso hectolítrico, sem afetar, entretanto, a produtividade.

Para o manejo com três cortes, portanto, as associações entre os grupos de caracteres mais relevantes foram estabelecidas pelo número de perfilhos totais e perfilhos férteis por planta. Assim, a seleção indireta deve usar esses caracteres para o aumento no número de espigas por metro quadrado, no número e na massa de grãos por espiga, na massa de mil grãos, no peso hectolítrico e na produtividade.

\section{Conclusões}

1. As relações canônicas entre os caracteres morfológicos e os componentes da produção de grãos de trigo (Triticum aestivum) de duplo propósito dependem do manejo de corte a que os genótipos estão submetidos.

2. O diâmetro do colmo principal, no manejo sem e com um corte, e o número de perfilhos e de perfilhos férteis, no manejo com dois e três cortes, são os caracteres morfológicos que devem ser priorizados na seleção de genótipos de trigo de duplo propósito superiores quanto à produtividade e ao peso hectolítrico.

\section{Agradecimentos}

À Coordenação de Aperfeiçoamento de Pessoal de Nível Superior (Capes), pela concessão de bolsa.

\section{Referências}

ALMEIDA, M.L. de; MUNDSTOCK, C.M. O afilhamento da aveia afetado pela qualidade da luz em plantas sob competição. Ciência Rural, v.31, p.393-400, 2001. DOI: 10.1590/ S0103-84782001000300005.

ALVES, A.C.; ALMEIDA, M.L. de; LIN, S.S.; VOGT, G.A. Emissão do afilho do coleóptilo em genótipos de aveia e em diferentes condições de estresses e manejo. Ciência Rural, v.34, p.385-391, 2004. DOI: 10.1590/S0103-84782004000200008. 
BORTOLINI, P.C.; SANDINI, I.; CARVALHO, P.C.F.; MORAES, A. de. Cereais de inverno submetidos ao corte no sistema de duplo propósito. Revista Brasileira de Zootecnia, v.33, p.45-50, 2004. DOI: $10.1590 / \mathrm{S} 1516-35982004000100007$.

BUTT, M.S.; ANJUM, F.M.; ZUILICHEM, D.V.; SHAHEEN, M. Development of predictive models for end-use quality of spring wheats through canonical analysis. International Journal of Food Science and Technology, v.36, p.433-440, 2001. DOI: 10.1046/j.1 365-2621.2001.00477.x.

CRUZ, C.D.; CARNEIRO, P.C.S. Modelos biométricos aplicados ao melhoramento genético. Viçosa: Ed. da UFV, 2003. 579p.

CRUZ, C.D.; REGAZZI, A.J. Modelos biométricos aplicados ao melhoramento genético. 2.ed. Viçosa: Ed. da UFV, 1997. 390p.

CRUZ, C.D.; REGAZZI, A.J.; CARNEIRO, P.C.S. Modelos biométricos aplicados ao melhoramento genético. 2.ed. Viçosa: Ed. da UFV, 2012. 514p.

ERAYMAN, M.; ABEYO, B.G.; BAENZIGER, P.S.; BUDAK, H.; ESKRIDGE, K.M. Evaluation of seedling characteristics of wheat (Triticum aestivum L.) through canonical correlation analysis. Cereal Research Communications, v.34, p.1231-1238, 2006. DOI: 10.1556/CRC.34.2006.4.263.

FALQUETO, A.R.; CASSOL, D.; MAGALHÃES JÚNIOR, A.M. de; OLIVEIRA, A.C. de; BACARIN, M.A. Crescimento e partição de assimilados em cultivares de arroz diferindo no potencial de produtividade de grãos. Bragantia, v.68, p.563-571, 2009. DOI: 10.1590/S0006-87052009000300002.

FIOREZE, S.L.; RODRIGUES, J.D. Perfilhamento do trigo em função da aplicação de regulador vegetal. Revista Brasileira de Ciências Agrárias, v.7, p.750-755, 2012. DOI: 10.5039/agraria. v7isa1923.

GONDIM, T.C. de O.; ROCHA, V.S.; SEDIYAMA, C.S.; MIRANDA, G.V. Análise de trilha para componentes de rendimento e caracteres agronômicos de trigo sob desfolha. Pesquisa Agropecuária Brasileira, v.43, p.487-493, 2008. DOI: 10.1590/S0100-204X2008000400007.

LOPES, M.S.; REYNOLDS, M.P.; JALAI-KAMALI, M.R.; MOUSSAC, M.; FELTAOUS, Y.; TAHIR, I.S.A.; BARMA, N.; VARGAS, M.; MANNES, Y.; BAUMF, M. The yield correlations of selectable physiological traits in population of advanced spring wheat lines grown in warm and drought environments. Field Crops Research, v.128, p.129-136, 2012. DOI: 10.1016/j. fcr.2011.12.017.

MARTIN, T.N.; SIMIONATTO, C.C.; BERTONCELLI, P.; ORTIZ, S.; HASTENPFLUG, M.; ZLECH, M.F.; SOARES, A.B. Fitomorfologia e produção de cultivares de trigo duplo propósito em diferentes manejos de corte e densidades de semeadura. Ciência Rural, v.40, p.1695-1701, 2010. DOI: 10.1590/ S0103-84782010000800004.

MARTIN, T.N.; STORK, L.; BENIN, G.; SIMIONATTO, C.C.; ORTIZ, S.; BERTONCELLI, P. Importância da relação entre caracteres em trigo duplo propósito no melhoramento da cultura. Bioscience Journal, v.29, p.1932-1940, 2013.
OZTURK, A.; CAGLAR, O.; BULUT, S. Growth and yield response of facultative wheat to winter sowing, freezing sowing and spring sowing at different seeding rates. Journal of Agronomy and Crop Science, v.192, p.10-16, 2006. DOI: 10.1111/j.1439-03 7X.2006.00187.x.

SANTOS, H.P.; MUSNDTOCK, C.M. Parâmetros da habilidade competitiva no estabelecimento de populações caracterizam o potencial de produção individual em trigo e aveia. Revista Brasileira de Botânica, v.25, p.43-53, 2002. DOI: 10.1590/ s0100-84042002000100007.

SILVA, S.A.; CARVALHO, F.I.F. de; NEDEL, J.L.; CRUZ, P.J.; SILVA, J.A.G. da; CAETANO, V. da R.; HARTWIG, I.; SOUSA, C. da S. Análise de trilha para os componentes de rendimento de grãos em trigo (Triticum aestivum L.). Bragantia, v.64, p.191-196, 2005. DOI: 10.1590/S0006-87052005000200004.

SILVEIRA, G. da; CARVALHO, F.I.F. de; OLIVEIRA, A.C. de; VALÉRIO, I.P.; BENIN, G.; RIBEIRO, G.; CRESTANI, M.; LUCHE, H. de S.; SILVA, J.A.G. da. Efeito da densidade de semeadura e potencial de afilhamento sobre a adaptabilidade e estabilidade em trigo. Bragantia, v.69, p.67-70, 2010. DOI: 10.1590/S0006-87052010000100009.

SOUZA, V.Q. de; NARDINO, M.; BONATO, G.O.; BAHRY, C.A.; CARON, B.O.; ZIMMER, P.D.; SCHIMIDT, D. Desfolha em diferentes estádios fenológicos sobre características agronômicas em trigo. Bioscience Journal, v.29, p.1905-1911, 2013.

STEEL, R.G.D.; TORRIE, J.H.; DICKEY, D.A. Principles and procedures of statistics: a biometrical approach. $3^{\text {rd }} \mathrm{ed}$. New York: McGraw Hill Book, 1997. 666p.

TAVAREZ, M.; MELO, A.M.T. de; SCIVITTARO, W.B. Efeitos diretos e indiretos e correlações canônicas para caracteres relacionados com a produção de pimentão. Bragantia, v.58, p.41-47, 1999. DOI: 10.1590/s0006-87051999000100006.

TOEBE, M.; CARGNELUTTI FILHO, A. Não normalidade multivariada e multicolinearidade na análise de trilha em milho. Pesquisa Agropecuária Brasileira, v.48, p.466-477, 2013. DOI: 10.1590/S0100-204X2013000500002.

VALÉRIO, I.P.; CARVALHO, F.I.F. de; OLIVEIRA, A.C. de; BENIN, G.; MAIA, L.C.; SILVA, J.A.G.; SCHMIDT, D.M.; SILVEIRA, G. da. Fatores relacionados à produção e desenvolvimento de afilhos em trigo. Semina: Ciências Agrárias, v.30, p.1207-1218, 2009.

VALÉRIO, I.P.; CARVALHO, FI.F. de; OLIVEIRA, A.C. de; MACHADO, A. de A.; BENIN, G.; SCHEEREN, P.L.; SOUZA, V.Q. de; HARTWIG, I. Desenvolvimento de afilhos e componentes do rendimento em genótipos de trigo sob diferentes densidades de semeadura. Pesquisa Agropecuária Brasileira, v.43, p.319-326, 2008. DOI: 10.1590/S0100-204X2008000300005.

VIEIRA, E.A.; CARVALHO, F.I.F. de; OLIVEIRA, A.C. de; MARTINS, L.F.; BENIN, G.; SILVA, J.A.G. da; COIMBRA, J.; MARTINS, A.F.; CARVALHO, M.F. de; RIBEIRO, G. Análise de trilha entre os componentes primários e secundários do rendimento de grãos em trigo. Revista Brasileira de Agrociência, v.13, p.169-174, 2007.

Recebido em 29 de dezembro de 2014 e aprovado em 15 de junho de 2015 